\title{
Corrigendum: Arousal and exposure duration affect forward step initiation
}

\author{
Daniëlle Bouman, John F. Stins * and Peter J. Beek \\ Department of Human Movement Sciences, Faculty of Behavioural and Movement Sciences, Vrije Universiteit Amsterdam, \\ MOVE Research Institute Amsterdam, Amsterdam, Netherlands
}

Keywords: emotion, motor activity, gait, reaction time, kinematics

\section{A corrigendum on}

Arousal and exposure duration affect forward step initiation by Bouman, D., Stins, J. F., and Beek, P. J. (2015) Front. Psychol. 6:1667. doi: 10.3389/fpsyg.2015.01667

In the original article we had added an image of a barking dog as part of Figure 1. This image was taken from the International Affective Picture System (IAPS; Lang et al., 2008). However, this was done without permission of the Center for the Study of Emotion and Attention, for which we apologize. For this reason we have now replaced Figure 1 with a modified version, whereby we removed said image.

\section{AUTHOR CONTRIBUTIONS}

All authors listed, have made substantial, direct and intellectual contribution to the work, and approved it for publication.

The original article was updated.

\section{REFERENCES}

\section{OPEN ACCESS}

Edited and reviewed by:

Mariska Esther Kret,

University of Amsterdam, Netherlands

*Correspondence: John F. Stins

j.f.stins@vu.nl

Specialty section: This article was submitted to

Emotion Science a section of the journal Frontiers in Psychology

Received: 19 January 2016 Accepted: 28 January 2016

Published: 04 February 2016

Citation:

Bouman D, Stins JF and Beek PJ (2016) Corrigendum: Arousal and exposure duration affect forward step

initiation. Front. Psychol. 7:164. doi: 10.3389/fpsyg.2016.00164
Lang, P. J., Bradley, M. M., and Cuthbert, B. N. (2008). International Affective Picture System (IAPS): Affective Ratings of Pictures and Instruction Manual. Technical Report A-6. University of Florida.

Conflict of Interest Statement: The authors declare that the research was conducted in the absence of any commercial or financial relationships that could be construed as a potential conflict of interest.

Copyright (c) 2016 Bouman, Stins and Beek. This is an open-access article distributed under the terms of the Creative Commons Attribution License (CC BY). The use, distribution or reproduction in other forums is permitted, provided the original author $(s)$ or licensor are credited and that the original publication in this journal is cited, in accordance with accepted academic practice. No use, distribution or reproduction is permitted which does not comply with these terms.

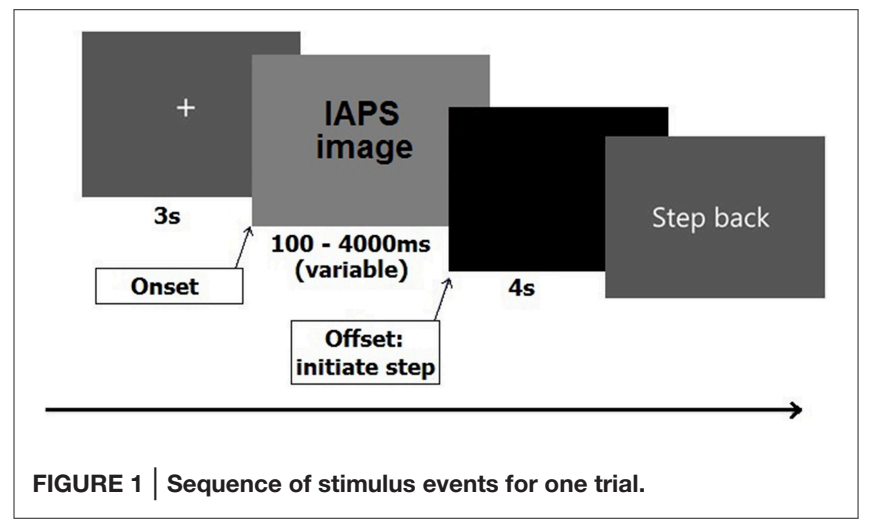

